\title{
Autologous Bone Marrow-Derived Mesenchymal Stem Cells for Tendon Repair in Horses: Experimental Study
}

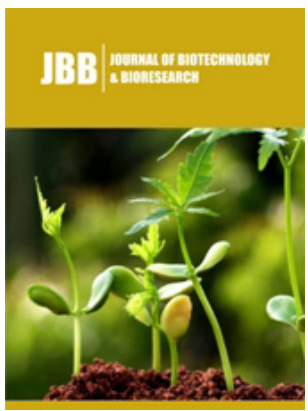

*Corresponding author: Shokry MM Department of Veterinary Surgery, Anesthesiology \& Radiology, Faculty of Veterinary Medicine, Cairo University, Egypt

Submission: 侮 September 29, 2021

Published: 海October 22, 2021

Volume 3 - Issue2

How to cite this article: Shokry MM*, Mostafa AA, Tohamy A, El-Sharkawi M. Autologous Bone Marrow-Derived Mesenchymal Stem Cells for Tendon Repair in Horses: Experimental Study. J Biotech Biores. 3(2). JBB. 000559. 2021.

Copyright@ Shokry MM, This article is distributed under the terms of the Creative Commons Attribution 4.0 International License, which permits unrestricted use and redistribution provided that the original author and source are credited.

\author{
Shokry MM ${ }^{1 *}$, Mostafa $\mathrm{AA}^{1}$, Tohamy $\mathrm{A}^{2}$ and El-Sharkawi $\mathrm{M}^{3}$ \\ ${ }^{1}$ Department of Veterinary Surgery, Egypt \\ ${ }^{2}$ Department of Forensic Medicine \& Toxicology, Faculty of Veterinary Medicine, Egypt \\ ${ }^{3}$ Equestrian Veterinary Hospital, Police Academy, Cairo, Egypt
}

\begin{abstract}
The Equine Superficial Digital Flexor Tendon (SDFT) is frequently in athletic injured horses. The current conventional treatment strategies produce limited results with poor repair quality and an extremely long convalescence. Recently, stem cell therapy has shown promising results to enhancing the healing process of many degenerative diseases. The present study aims to evaluate the effect of autologous mesenchymal bone Marrow-Derived Stem Cells (MSCs) in the healing of collagenase-induced SDFT tendonitis lesions in both forelimbs of 5 horses. The injured tendons of the right forelimbs were treated by injection of autologous MSCs and the injured tendons of the other left forelimbs were injected with saline. The horses were clinically, ultrasonography and morpho-histology evaluated at 2, 4, 8, 12 \&16 weeks. Horses were euthanized after 16 weeks. Results proved the potential of autologous MSCs to accelerating tendon repair in terms of quality and time. The success of treatment was proven by the shortened rehabilitation time and the higher number of horses returning to normal activity
\end{abstract}

Keywords: Equine; Stem cells; Tendons; Ligaments; Ultrasound

\section{Introduction}

Tendon lesions are a major cause of lameness and reduced performance in athletic horses and may result in the early termination of the animal's career with subsequent significant economic loss and animal welfare [1]. Injury of the Superficial Digital Flexor Tendon (SDFT) is the most common tendon injury in the sport horse and it occurs most frequently in the race horses and occur commonly in the center of the unsheathed portion of the SDFT [2,3]. Approximately $70 \%$ of race horses having tendon injuries (largely to the SDFT) failed to return to previous level of performance in any race [4]. Re-injury rates of $23-67 \%$ have been reported in various equine sports disciplines; $19-70 \%$ are ultimately retired due to original or the subsequent re-injury [5-9]. Conventional treatments for tendonitis are basically clinical and surgical approaches. However, the recovered animals are rarely sufficiently healed to allow their return to competitive with a performance similar to that observed when they were healthy [10]. Currently regenerative medicine has significantly evolved and stimulated investigations of methods for modulating tendon healing that provided better repair consistent with original tendon architecture [11,12]. Adult tissue derived stem cells have emerged as injectable potentially multi-potent cells that have the capability of differentiating and participating in the healing of various musculoskeletal tissues, including tendons [13-16]. The objective of the present study was to clinically, ultrasonography and morpho-histopathology evaluate the effect of autologous Mesenchyme Stem Cells (MSC) in the treatment of horses with experimentally induced collagenase tendonitis.

\section{Materials and Methods}

Five adult athletic clinically normal horses ( 3 males and 2 females) of a median weight $350 \mathrm{Kg}$ ( 4 to 10 years old) of mixed breeds were used in this model. The horses were examined clinically and ultrasonography to rule out any signs of tendon injury or lameness. The 
study was approved by the Cairo University Institutional Animal Care and Use Committee (CU-IACUC) (CU/II/F/27/2017). The horses were kept in the Equestrian Veterinary Section Stables of Police Academy. Inclusion criteria in the study were the absence of lameness and of forelimb superficial digital flexor lesions. All tendons were also examined ultrasonography to confirm their soundness. The presented horses were lightly sedated with IV dose of xylazine $\mathrm{HCl}-(1.1 \mathrm{mg} / \mathrm{Kg}$ ) (Xylaject $2 \% ®$ - ADWIA Co. Egypt). The superficial digital flexor tendon SDFT of the forelimbs of the horses were subjected to initial ultrasonography examination with a linear probe at $12 \mathrm{MHz}$ (Sonoscape AV6 Co., Ltd. Shenzhen 51805.P R, China) to document the normal status of their sound flexor tendons as a base line.

\section{Induction of the tendon lesion}

This stage was carried out before the starting of MSCs therapy by 2 weeks. Collaginase-induced core lesions (collagenase $1.0 \mathrm{ml}, 2.5 \mathrm{mg} / \mathrm{ml}$ ) (Sigma pharmaceuticals- USA), by injection at the center of the SDFTs, were performed in the all forelimbs under ultrasonography guide after IV xylazine sedation $1.1 \mathrm{mg} /$ kg) (XYLA-JECT@-ADWIA Pharmaceuticals Co.) combined with regional blocking of the proximal palmar nerves with $2 \%$ lidocaine $\mathrm{HCl}$ (Debocain ${ }^{\circledR}$ 2\%-the Arab company for pharmaceuticals, Egypt). IV Phenylbutazone, as a nonsteroidal anti-inflammatory agent
(4.4mg/Kg) (Phenyloject ADWIA Co. Egypt) was administered after collagenase injection and continued for 3 days every 24 hours to prevent any discomfort following the procedure.

\section{Bone marrow harvest}

The Bone Marrow (BM) was harvested from each horse was standing in stock after IV xylazine sedation. The sternum was palpated from the point between the fore limbs caudally to identify the three most caudal sternebrae by the appearance of their intersternebral spaces. This location band overlying the sternum was clipped, scrubbed and subcutaneously infiltrated with $2 \%$ lidocaine $\mathrm{HCl}$. Under ultrasound guide, the 5 th sternebra was located and its skin was infiltrated with local anesthetic. Under aseptic condition, a small stab incision was made through the skin and an 11-gauge, $10 \mathrm{~cm}$ biopsy needle Jamshidi biopsy needle (Medax medical device, Poggio Rusco, Italy) was introduced through the stab skin incision, for about 4-5 cm until contact was made with the sternebra and then cautious pushing of the needle for a further of $3 \mathrm{~cm}$ interiorly in the sternbrae to inter the BM sinus where $10 \mathrm{ml}$ of BM were then collected using syringes preloaded with $2.0 \mathrm{ml}$ of heparin of $(15,000 \mathrm{IU} / \mathrm{ml})$ (Cal-Heparine ${ }^{\circ}$, Global Pharmaceutical industry, Egypt). (Figure 1) The skin wound was then closed by one stitch. The MB sample was then shipped to cytology laboratory in ice box for Mesenchyme Stem Cells (MSCs) isolation and culture.

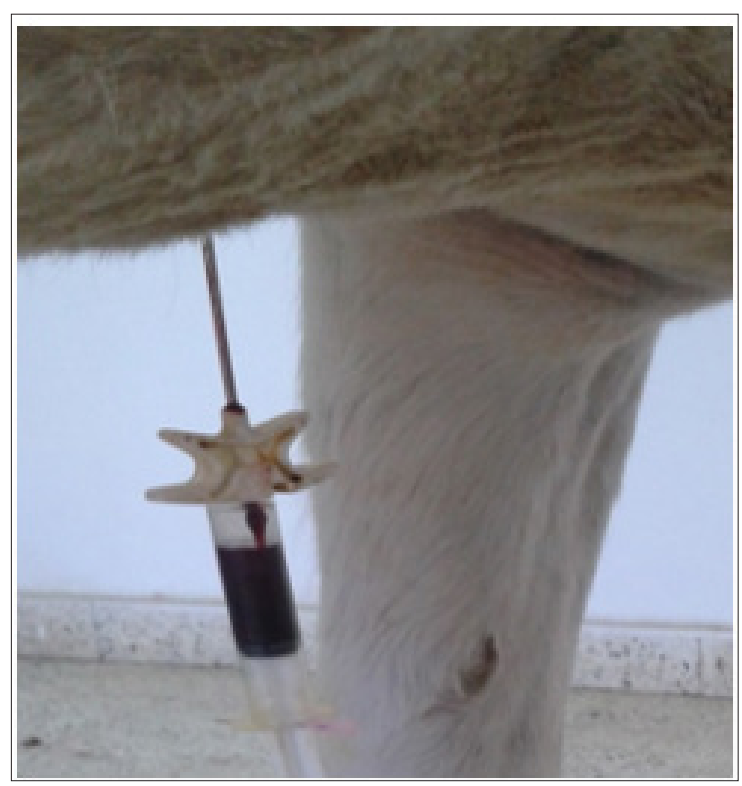

Figure 1: Collection of sternal bone marrow by Jamshidi biopsy needle.

\section{MSCs isolation and culture}

Each volume of bone marrow aspirate was diluted with equal volumes of Dulbecco's modified Eagle's Medium, (DMEM) (Gibco, UK). A total of $30 \mathrm{ml}$ diluted aspirate was loaded on $9 \mathrm{ml}$ of Ficolhypaque (Lymphopreb, Oslo, Norway), centrifuged at 1500rpm for 25 minutes at room temperature and then the interphase collected after aspirating and discarding the supernatant. The interphase Mono Nuclear Cell Fraction (MNCF) was washed with $9 \mathrm{ml}$ phosphate buffered saline (PBS) and centrifuged at 2200rpm for 8 minutes. The supernatant part was discarded and the cells were then washed once again with PBS at $2100 \mathrm{rpm}$ for 6 minutes. The cells were plated with a cell density of $100,000 / \mathrm{cm}^{2}$ in T25 flasks containing $5 \mathrm{ml}$ Dulbecco Modified Eagle Medium (DMEM) to which added fetal bovine serum (FBS10\%) Gibco, UK) and 1\% penicillinstreptomycin (Sigma-Aldrich, USA). Then, the cultures were incubated at $37^{\circ} \mathrm{C}$ in a humidifies atmosphere (95\%) containing $5 \%$ CO2. When the cells reached $80-90 \%$ confluence, the adherent cells were washed twice in PBS, detached using (0.05\% Trypsin/ 
EDTA 1×) (Sigma-Aldrich, USA) and replated according to standard cultural technique at 1:4 dilution. Cell counting was performed after the colony-forming units were established and at confluence after first passage to reach $(10 \times 106$ cells in each $1.0 \mathrm{ml})$. (Figure 2$)$. To provide osteogenic conditions, the culture medium of the confluent at passage 3 was substituted with osteogenic medium for 2 weeks while the media was changed every 3 days. Alzarin red stain as a biochemical essay to determine colorimetrically the presence of calcified deposits inside the cells. Reverse transcription-Polymerase Chain Reaction (PCR) was performed to detect the production of mineralized matrix specific antibodies. At day (0) (two weeks after the induction of tendon lesion). MSC therapies were administered into the collagenase-developed core lesions of the SDFT tendons of the forelimbs (test tendons). Sterile normal saline $1.0 \mathrm{ml}(0.9 \%)$ was administered into the collagenase-developed core lesions of the contralateral SDFT tendons of the forelimbs of the same horses (control tendons) under ultrasound guide. Clinical and ultrasound examinations were performed every 2 weeks until the end of the study by the $16^{\text {th }}$ week. Thereafter biopsies of the involved SDFT were done for histopathology.

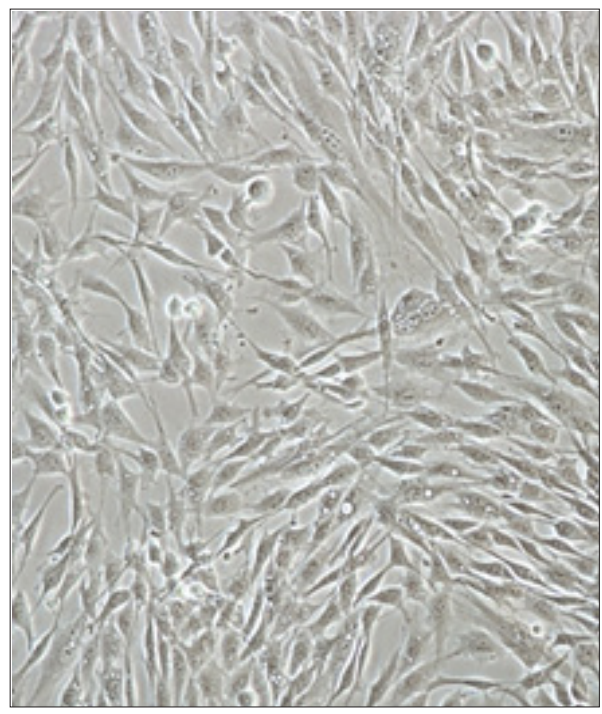

Figure 2: Showing morphology of equine cultured BM-MSCs

\section{MSCs therapy}

At day 0 (2 weeks after the induction of tendon lesion), all the horses were sedated with IV dose of xylazine $(1.1 \mathrm{mg} / \mathrm{kg})$ combined with blocking of palmar nerves. The sites of injection were prepared aseptically. A $22-\mathrm{G} / 1.25 \mathrm{~cm}$ needle was used for delivery of MSCs therapy which was inserted in the core lesion from the lateral aspect of SDFT under ultrasound guide, $1 \mathrm{ml}$ of autologous bone marrow-derived MSCs suspension (10×106 MSC) diluted with autologous serum were injected into the induced core lesions of the 5 right SDFTs (test tendons). Sterile normal saline $0.9 \%(1 \mathrm{ml})$ was also injected into the other contralateral 5 left SDFTs core lesions (control tendons). Sterile bandages were then applied. The horses of the experimental model were subjected to stable confinement for 2 weeks and then for rehabilitation program started from the $3^{\text {rd }}$ week to $16^{\text {th }}$ as follows: Week 3 to 5 : hand walking for 10 minutes, once daily, Week 6 to 8 : hand walking for 10, twice daily, Week 9 to 11: hand walking for 20 minutes, once daily, Week 12 to 16: hand walking 20 minutes, twice daily.

\section{Clinical evaluation}

All horses of the experimental model were visually daily examined to evaluate any local inflammatory changes as well as the lameness degree at 4, $6 \& 8$ weeks from therapy. Any observed changes were scored according to the degree of intensity (0) normal (1) mild, (2),moderate; and (3) severe. The degree of lameness was rated according to the AAEP (American Association Equine Practitioners) lameness grading system from 0 to 5 as: (0) Lameness not perceptible under any circumstance ,(1) Lameness is difficult to observe and is not consistently apparent, regardless of circumstances, (2) Lameness is difficult to observe at a walk, or when trotting in a straight line, but consistently apparent under certain circumstances, (3) Lameness is consistently observable at a trot under all circumstances,(4) Lameness is obvious at a walk, (5) Lameness produces minimal weight bearing in motion and/or at rest or a complete inability to move.

\section{Ultrasonography evaluation}

All the horses of the experimental model were ultrasonography evaluated throughout the timeline of the experiment at (week 2, 4, 8 \&16). Ultrasonography images documented prior to the tendon injury induction were used as control images. All ultrasonography examination were performed under IV light sedation with xylazine $(1.1 \mathrm{mg} / \mathrm{kg})$. The palmar mid-metacarpal regions were clipped before the application of coupling gel. Segmental tendon transverse and sagittal images were obtained to evaluate the SDFT status in terms of: 
1. The percentage of the cross-sectional lesion size area (MIZ) (lesion area / tendon area X 100).

2. The fiber linear alignment pattern degree in the sagittal images: (0) Parallel fiber pattern in $76-100 \%$ of the fibers, (1)Parallel fiber pattern in 51-75\% of the fibers,(2)Parallel fiber pattern in $26-50 \%$ of the fibers,(3)Parallel fiber pattern in $0-25 \%$ of the fibers.

3. The echogenicity grads in the cross-sectional image based on the scale: (0) Normal to near normal echogenicity, (1) 25-50\% loss of echogenicity, (2) $50 \%$ loss of echogenicity, (3) mostly to complete anechoic.

\section{Morpho-histopathology evaluation}

The five enrolled experimental horses were euthanized by the $16^{\text {th }}$ week after MSCs therapy by administration of an overdose of barbiturate. The harvested tendons were morphologically evaluated. Portions of the tendon in which the lesion were located transected. Combined with the adjacent sound tendon pieces transected from SDFT of the hind limbs. All tendon pieces were placed in $10 \%$ neutral buffered formalin solution. Then they were processed through the routine methods for paraffin embedded tissue and then 3millimicron sections were stained with hematoxyline and eosin (H\&E) and Masson's trichrome stain. Histopathology examination was performed with light optical microscope at $10 \mathrm{X}$ or $400 \mathrm{X}$ magnification. Histological analysis was based on scores as described by Nixon et al. [15] as follows:

0 : (normal) the collagen fiber appeared closely packed parallel and thick bundles, the fibroblast appeared as linear shape, with flattened nuclei arranged on the periphery of the collagen bundles. No evidence of any

Vascularization or hemorrhage.

1. (Mild) slightly oval shape and increased density of tendon cells, uneven hemorrhage, slight increased vascularization, slight increased inflammatory infiltration and $>20 \%$ collagen fibers linearity.

2. (Moderate) moderately round shape and density tendon cells, multiple hemorrhagic areas, moderately increased vascularization and inflammatory cell infiltrate and 20\% to $50 \%$ collagen fibers linearity.

3. (Severe) almost round shape and high density tendon cells predominantly hemorrhagic with high vascularization and inflammatory cell infiltrate and absence of collagen fibers linearity.

\section{Statistical analysis}

Clinical and ultrasonographic examination were converted to scores, grades and scales were statistically analyzed using software (Graphpad-Prism, version 7 ,California, USA) by application of a repeated-measures ANOVA was used to test the main effects of treatment and time. Non-parametric Wilcoxon to analyse the data expressed in scores. A value of $\mathrm{P}<0.05$ was considered significant.

\section{Results}

In the present study, the adopted technique for equine bone marrow harvest from the sternum using Jamshidi needles under ultrasound guide while the horses in standing position and sedated was feasible and successful for collecting ample amounts of bone marrow from each horse without complication. The created sternal wounds were healed uneventfully. The MSCs were separated, layered and expanded for the generation of colony-forming units of MSCs ready for implantation in the next stages.

\section{Isolation and cultivation of MSCs}

MSCs isolation, layered and expansion procedure time of 2 weeks was sufficient to produce the necessary number of MSCs with high viable stem cells (10 X106) for cell therapy. In which, after 5 days of culture, the number of viable stem cells ranged from (3 $\mathrm{X} 106$ to $10 \mathrm{X} 106$ mean $=4 \mathrm{X} 106$ ) with a cell viability greater than $96 \%$ in all of the samples and by 2 weeks of cell culture, the number of viable cells ranged from (14 X106) to $(22 \mathrm{X106})$ with a mean of (16X106) with cell viability greater than $98 \%$ (Figure 1). The horses of the experimental model presented normal SDFTs upon inspection and their ultrasound views exhibited normal echogenic pattern and fiber alignment of their tendon.

\section{Induction of SDFT core lesions}

Collagenase induced SDFT core lesions in the horses of the experimental model developed within the first 24 hours and continued for one week and recognized by local hyperthermia, local detectable diffuse swelling $\pm 0.18 \mathrm{~cm}$ ) at the palmar aspect of the mid-metacarpal region, local obvious pain reaction (tenderness) with mean recorded scores $(3.0 \pm 0.0)$ by digital palpation, and high degree of lameness with mean recorded scores $(3.40 \pm 0.55)$. Ultrasonography of collagenase-induced tendon core lesions showed core lesions of variable sizes with significant loss of echogenicity scores $(3.20 \pm 0.45)$, fiber alignment scores $(3.00 \pm 0.00)$ and increase of MIZ \% (56.0 \pm 0.02$)$ within two week from induction.

\section{Clinical findings}

Intra-lesional implantation of autologous BM-MSCs in the test tendons and saline in the control tendons of the experimental model at (day -0) was successfully performed under ultrasound guide. Repeated clinical evaluations at 2,4,8,12 and 16 weeks following injection of autologous MSCs (test tendons) and saline (control tendons) demonstrated gradual non-significant decrease of lameness scores, local swelling and temperature while the pain scores showed mild gradual decrease and disappeared completely by the 10 - week in the test group. (Graphs $1 \& 2$ ) (Table 1). 
Table 1: Summary of clinical, ultrasonography, and histopathology evaluations at different time intervals, in horses of the experimental model (test and control).

\begin{tabular}{|c|c|c|c|c|c|c|c|c|c|c|c|c|c|c|}
\hline \multirow[b]{2}{*}{ Evaluation } & \multicolumn{8}{|c|}{ Test-Treated Tendons Week } & \multicolumn{6}{|c|}{ Control Tendons Week } \\
\hline & -2 & $\mathbf{0}$ & 2 & 4 & 8 & 12 & 16 & -2 & $\mathbf{0}$ & 2 & 4 & 8 & 12 & 16 \\
\hline $\begin{array}{l}\text { Local heat } \\
\text { score }\left(\mathrm{C}^{\circ}\right)\end{array}$ & $\begin{array}{c}35.9 \pm \\
011\end{array}$ & $\begin{array}{c}38.9 \pm \\
0.11\end{array}$ & $\begin{array}{c}37.6 \\
\pm \\
0.49\end{array}$ & $\begin{array}{c}36.2 \pm \\
0.21\end{array}$ & $\begin{array}{c}36.0 \\
\pm \\
0.05\end{array}$ & $\begin{array}{c}36.0 \pm \\
0.00\end{array}$ & $\begin{array}{c}36.0 \pm \\
0.00\end{array}$ & $\begin{array}{c}36.1 \pm \\
0.12\end{array}$ & $\begin{array}{l}38.8 \pm \\
0.21\end{array}$ & $\begin{array}{c}* \\
38.7 \pm \\
0.22\end{array}$ & $\begin{array}{c}* \\
38.0 \pm \\
0.08\end{array}$ & $\begin{array}{c}37.2 \pm \\
0.38\end{array}$ & $\begin{array}{c}36.6 \\
\pm \\
0.16\end{array}$ & $\begin{array}{c}36.2 \pm \\
0.11\end{array}$ \\
\hline $\begin{array}{l}\text { Local } \\
\text { swelling } \\
\text { dorso-pal- } \\
\text { mar tendon } \\
\text { thickening } \\
(\mathrm{cm})\end{array}$ & $\begin{array}{c}7.30 \pm \\
0.21\end{array}$ & $\begin{array}{l}10.52 \\
\pm 0.19\end{array}$ & $\begin{array}{c}9.64 \\
\pm \\
0.29\end{array}$ & $\begin{array}{c}8.76 \pm \\
0.30\end{array}$ & $\begin{array}{c}8.22 \\
\pm \\
0.30\end{array}$ & $\begin{array}{l}7.52 \pm \\
0.19\end{array}$ & $\begin{array}{c}7.48 \pm \\
0.20\end{array}$ & $\begin{array}{l}7.14 \pm \\
0.21\end{array}$ & $\begin{array}{c}10.56 \pm \\
0.2\end{array}$ & $\begin{array}{c}* \\
11.44 \pm \\
0.4\end{array}$ & $\begin{array}{c}* \\
10.72 \pm \\
0.4\end{array}$ & $\begin{array}{c}* \\
10.08 \pm \\
0.26\end{array}$ & $\begin{array}{c}* \\
9.48 \\
\pm \\
0.26\end{array}$ & $\begin{array}{l}8.72 \pm \\
1.21\end{array}$ \\
\hline \multicolumn{15}{|c|}{ Clinical } \\
\hline $\begin{array}{l}\text { Local pain } \\
\text { score }\end{array}$ & $\begin{array}{c}0.00 \pm \\
0.00\end{array}$ & $\begin{array}{c}3.00 \pm \\
0.00\end{array}$ & $\begin{array}{c}2.40 \\
\pm \\
0.55\end{array}$ & $\begin{array}{c}1.80 \pm \\
0.45\end{array}$ & $\begin{array}{c}1.20 \\
\pm \\
0.45\end{array}$ & $\begin{array}{c}0.20 \pm \\
0.45\end{array}$ & $\begin{array}{l}0.0 \pm \\
0.00\end{array}$ & $\begin{array}{l}0.00 \pm \\
0.00\end{array}$ & $\begin{array}{l}3.0 \pm \\
0.00\end{array}$ & $\begin{array}{c}* \\
3.0 \pm \\
0.00\end{array}$ & $\begin{array}{c}* \\
3.0 \pm \\
0.05\end{array}$ & $\begin{array}{c}* \\
2.6 \pm \\
0.55\end{array}$ & $\begin{array}{c}* \\
1.80 \\
\pm \\
0.45\end{array}$ & $\begin{array}{c}* \\
1.20 \pm \\
0.45\end{array}$ \\
\hline $\begin{array}{l}\text { Lameness } \\
\text { score }\end{array}$ & $\begin{array}{l}0.00 \pm \\
0.00\end{array}$ & $3.4 \pm$ & $3.0 \pm$ & $2.0 \pm$ & $1.4 \pm$ & $0.4 \pm$ & $0.2 \pm$ & $\begin{array}{c}0.00 \pm \\
0 .\end{array}$ & $3.4 \pm$ & $3.4 \pm$ & $3.2 \pm$ & $2.8 \pm$ & $2.8 \pm$ & $2.8 \pm$ \\
\hline \multirow{2}{*}{$\begin{array}{l}\text { Tendon } \\
\text { lesion size } \\
\text { (MIZ)\% }\end{array}$} & 0 & 0.55 & 0.71 & 0.71 & 0.55 & 0.55 & 0.45 & 0 & 0.55 & 0.55 & 0.45 & 0.45 & 0.45 & 0.45 \\
\hline & $\begin{array}{c}0.00 \pm \\
0.00\end{array}$ & $\begin{array}{c}58.0 \pm \\
0.01\end{array}$ & $\begin{array}{c}38.0 \\
\pm \\
0.03\end{array}$ & $\begin{array}{c}30.0 \pm \\
0.18\end{array}$ & $\begin{array}{c}22.0 \\
\pm \\
0.02\end{array}$ & $\begin{array}{c}12.0 \pm \\
0.01\end{array}$ & $\begin{array}{l}10.0 \pm \\
0.01\end{array}$ & $\begin{array}{l}0.00 \pm \\
0.00\end{array}$ & $\begin{array}{l}56.0 \pm \\
0.02\end{array}$ & $\begin{array}{c}* \\
50.0 \pm \\
0.03\end{array}$ & $\begin{array}{c}* \\
45.0 \pm \\
0.03\end{array}$ & $\begin{array}{c}* \\
41.0 \pm \\
0.02\end{array}$ & $\begin{array}{c}* \\
38.0 \\
\pm \\
0.02\end{array}$ & $\begin{array}{c}* \\
37.0 \pm \\
0.02\end{array}$ \\
\hline $\begin{array}{l}\text { Echogenicity } \\
\text { score }\end{array}$ & $\begin{array}{c}0.00 \pm \\
0.00\end{array}$ & $\begin{array}{l}3.0 \pm \\
0.00\end{array}$ & $\begin{array}{l}2.4 \pm \\
0.55\end{array}$ & $\begin{array}{l}2.0 \pm \\
0.00\end{array}$ & $\begin{array}{l}1.2 \pm \\
0.45\end{array}$ & $\begin{array}{l}0.4 \pm \\
0.55\end{array}$ & $\begin{array}{l}0.2 \pm \\
0.45\end{array}$ & $\begin{array}{l}0.00 \pm \\
0.00\end{array}$ & $\begin{array}{l}3.0 \pm \\
0.00\end{array}$ & $\begin{array}{c}* \\
3.0 \pm \\
0.00\end{array}$ & $\begin{array}{c}* \\
2.8 \pm \\
0.45\end{array}$ & $\begin{array}{c}* \\
2.6 \pm \\
0.55\end{array}$ & $\begin{array}{c}* \\
2.4 \pm \\
0.55\end{array}$ & $\begin{array}{c}* \\
2.0 \pm \\
0.00\end{array}$ \\
\hline \multicolumn{15}{|c|}{ US } \\
\hline $\begin{array}{l}\text { Fibers align- } \\
\text { ment pattern }\end{array}$ & $\begin{array}{l}0.00 \pm \\
0.00\end{array}$ & $\begin{array}{l}3.0 \pm \\
0.00\end{array}$ & $\begin{array}{l}2.2 \pm \\
0.45\end{array}$ & $\begin{array}{l}1.8 \pm \\
0.45\end{array}$ & $\begin{array}{l}1.2 \pm \\
0.45\end{array}$ & $\begin{array}{l}0.4 \pm \\
0.55\end{array}$ & $\begin{array}{l}0.2 \pm \\
0.45\end{array}$ & $\begin{array}{l}0.00 \pm \\
0.00\end{array}$ & $\begin{array}{c}* \\
3.0 \pm \\
0.00\end{array}$ & $\begin{array}{c}* \\
3.0 \pm \\
0.00\end{array}$ & $\begin{array}{c}* \\
3.00 \pm \\
0.00\end{array}$ & $\begin{array}{c}* \\
2.60 \pm \\
0.55\end{array}$ & $\begin{array}{c}* \\
2.4 \pm \\
0.55\end{array}$ & $\begin{array}{c}* \\
2.0 \pm \\
0.00\end{array}$ \\
\hline $\begin{array}{l}\text { Tend..cell } \\
\text { shape score }\end{array}$ & & & & & & & $\begin{array}{l}1.0 \pm \\
0.00\end{array}$ & & & & & & & $\begin{array}{c}* \\
2.25 \pm \\
0.5\end{array}$ \\
\hline $\begin{array}{l}\text { Hemorrhage } \\
\text { score }\end{array}$ & & & & & & & $\begin{array}{c}0.75 \pm \\
0.50\end{array}$ & & & & & & & $\begin{array}{c}* \\
2.25 \pm 0.5\end{array}$ \\
\hline \multicolumn{15}{|c|}{ H/path. } \\
\hline $\begin{array}{l}\text { Vasculariza- } \\
\text { tion score }\end{array}$ & & & & & & & $\begin{array}{c}0.75 \pm \\
0.50\end{array}$ & & & & & & & $\begin{array}{c}* \\
2.50 \pm \\
0.57\end{array}$ \\
\hline $\begin{array}{l}\text { Collagen fi- } \\
\text { bers linearity } \\
\text { score }\end{array}$ & & & & & & & $\begin{array}{c}0.75 \pm \\
0.50\end{array}$ & & & & & & & $\begin{array}{c}* \\
2.25 \pm \\
0.5\end{array}$ \\
\hline
\end{tabular}


1. Local heat: Normal $\left(\leq 36 \mathrm{C}^{\circ}\right)$, Mild $\leq\left(37 \mathrm{C}^{\circ}\right)$, Moderate $\left(\leq 38 \mathrm{C}^{\circ}\right)$ and Severe $\left(\leq 39 \mathrm{C}^{\circ}\right)$.

2. Local swelling score: Measuring the width of the swollen tendon in "cm" using a caliper gauge.

3. Local pain score (digital pressure on the tendon lesion): (0) No pain, (1) Mild pain, (2) Moderate pain, (3) Severe pain.

4. Lameness score: (0) No lameness, (1) Lameness is difficult to observe, (2) Lameness on exercise, (3) Lameness on trotting, (4) Lameness on walking, (5) Supporting lameness.

5. Tendon lesion area MIZ\% (lesion area / tendon area X 100).

6. Echogenicity score: (0) Normal echogenicity (<25\% loss of echogenicity), (1) $25-50 \%$ loss of echogenicity, (2) $\geq 50 \%$ loss of echogenicity, (3) Mostly to completely anechoic.

7. Liner fiber Pattern: (0) Aligned/parallel pattern in $>75 \%$ of the fibers, (1) Parallel pattern in $51-75 \%$ of the fibers, (2) Parallel pattern in 25-50\% of the fibers, (3) Parallel pattern in $<25 \%$ of the fibers.

8. Tendon cell shape score: (0) Normal linear fibroblast, (1) Slightly oval fibroblast, (2) Moderately round fibroblast, (3) Almost round fibroblast.

9. Hemorrhage score: (0)No hemorrhage, (1)Mild hemorrhage, (2)Moderate, (3)Severe hemorrhage.

10. Vascularization score: (0)No vascularization, (1)Mild vascularization, (2)Moderate vascularization, (3)Severe vascularization.

11. Collagen linearity: (0) Full linearity (normal parallel and thick bundles), (1) Linearity in $>50 \%$ of collagen fibers, (2) $=$ Linearity in $20-50 \%$ of collagen fibers, (3) Linearity in $<20 \%$ of collagen fibers.

12. * Significant at $\mathrm{p}<0.05$.

13. US : Ultrasonographhy

14. $\mathrm{H} /$ path : Histopathology

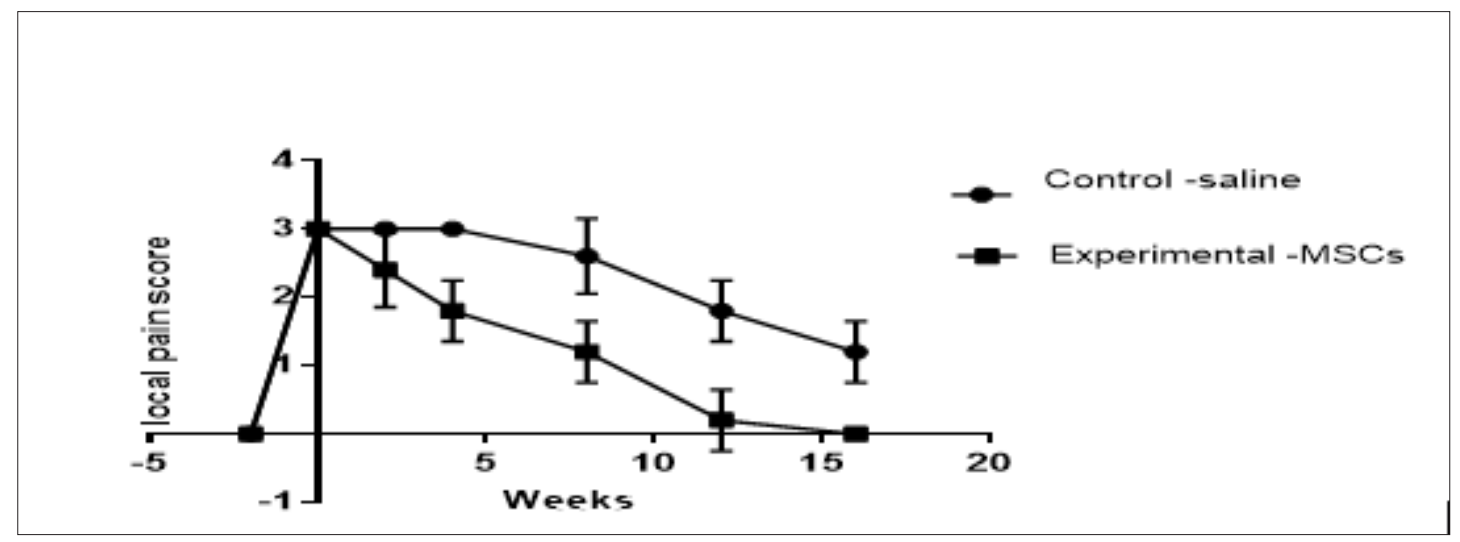

Graph 1: Local pain score

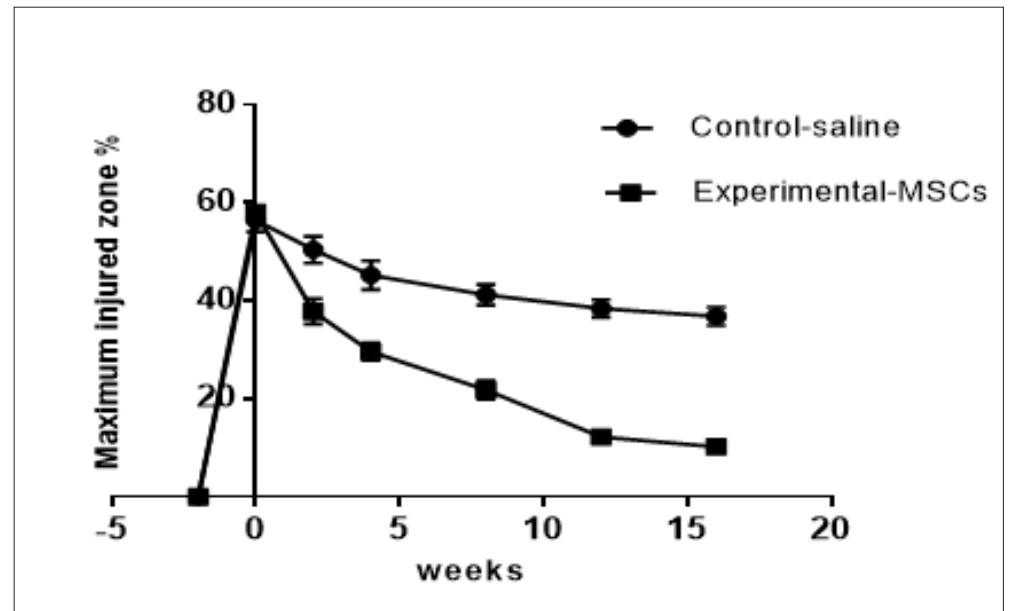

Graph 2: Lameness score. 


\section{Ultrasonography findings}

Quantitative analysis of tendon ultrasonography scales in terms of core lesion size, echogenicity and linear fiber alignment at different time intervals were as follow: At week (0),cross section and longitudinal ultrasound images showed tendon core lesions of variable size from hypoechoic to anechoic with loss of the linear fiber alignment pattern. The tendons of the test MSCsgroup showed significant gradual improvement at all scales i.e., echogenicity, MIZ\% and fiber alignment starting by the $2^{\text {nd }}$ week and reaching the best scales by the week-16, while the tendons of the control saline-group showed no marked changes (Graphs 3-5) (Table 1).

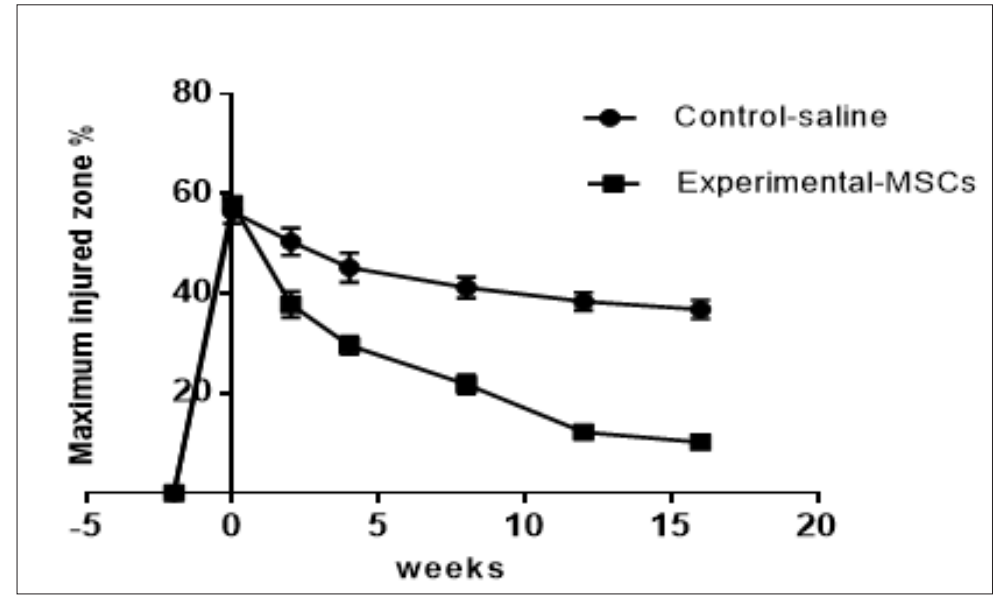

Graph 3: US Maximum injury score\%.

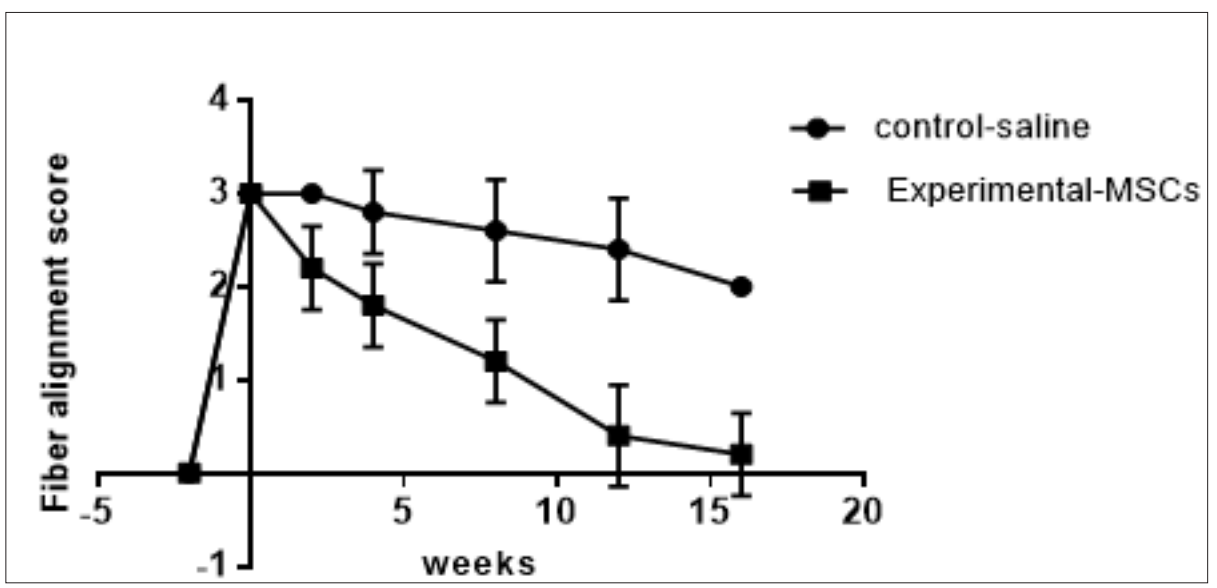

Graph 4: Fiber alignment score.

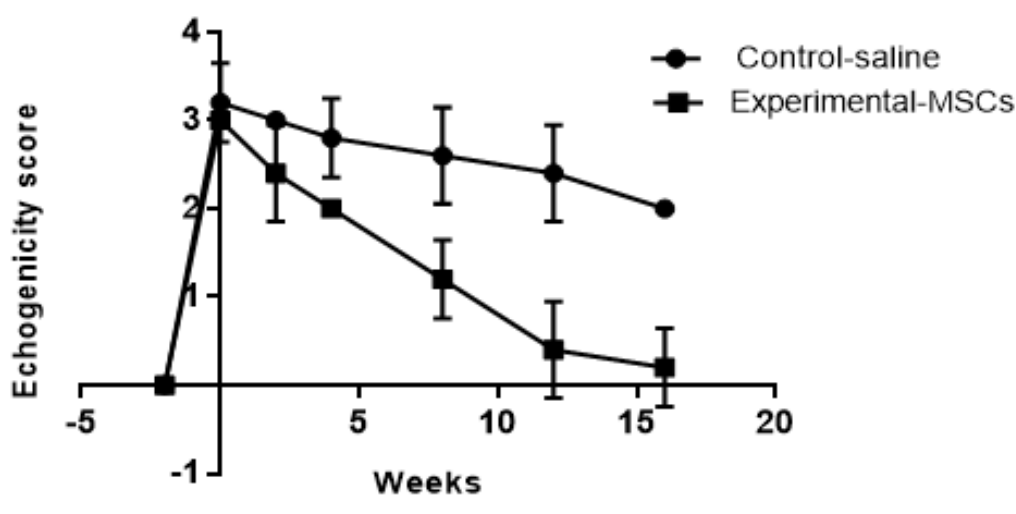

Graph 5: Echogenicity score. 


\section{Morpho-histology Findings}

\section{Morphology}

Gross morphological examination of the treated tendons of the horses of the experimental model after euthanasia at 16-week, revealed that the superficial epitenon of the MSCs treated tendon (test group) showed mild degree of adhesion. The paratenon was thin and transparent while, the tendon striation pattern could be detected. Transverse sections revealed ill-marked tendon core lesion. Saline-treated tendon (control group) showed marked core lesion, which appeared reddish to pink in color combined with sever degree of epitenon adhesion, thickened tendons and loss of the tendon striation pattern.

\section{Histopathology}

Longitudinal and transvers section stained with H\&E and Masson's trichrome were analyzed and scored. Overall, the healing scores in terms of : tendon cells shape, hemorrhage, vascularization and collagen fiber linearity for MSCs test group treated tendons showed significant improving when compared with the control saline treated group and interpreted by better organization of tendon fibers, reduced WBCs infiltrates and marked improvement of linearity the collagen fibers uniformity and crimping. Moreover, loss of cross linking of collagen fibers was apparent in the central bundles of tendon fibers of test MSCs group tendons (Figure 2-5), (Graph 6) and (Table1).

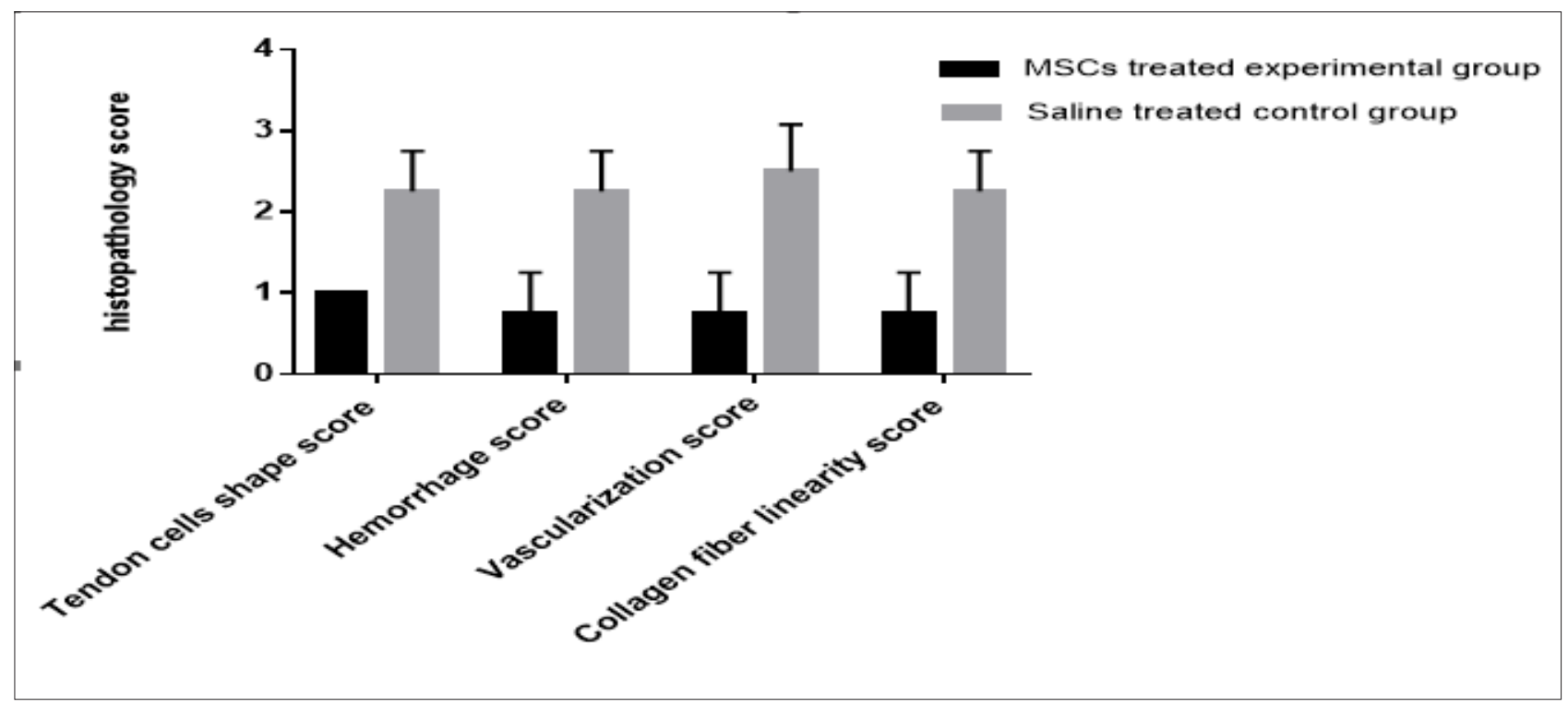

Graph 6: Histopathology score

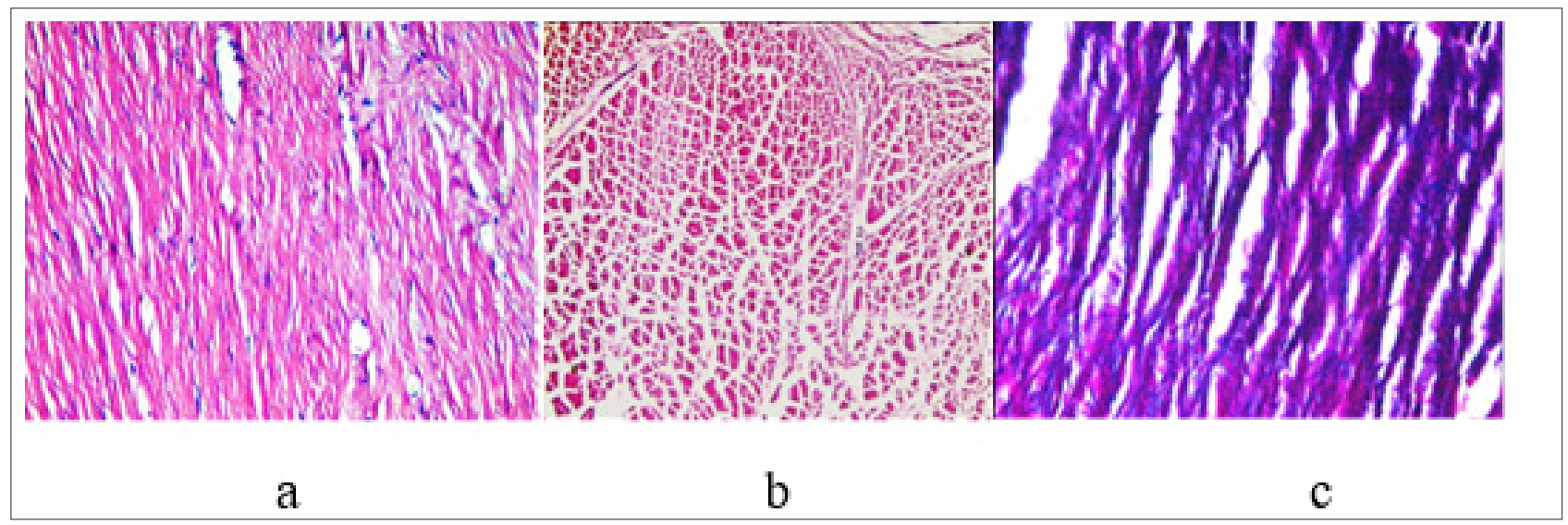

Figure 3a: Longitudinal section of SDFT after MSCs therapy after 16 weeks showing mild histopathological appeared as slightly oval shape and increased density of tendon cells, uneven hemorrhage, slight increased vascularization, slight increased inflammatory infiltration and $>50 \%$ collagen fibers linearity (H\&E\& X 60). Figure 3b: Cross section of SDFT after MSCs therapy (H\&E\& X 60).

Figure 3c: Longtudinal section of SDFT after MSCs therapy (Masson's trichrome X 60). 


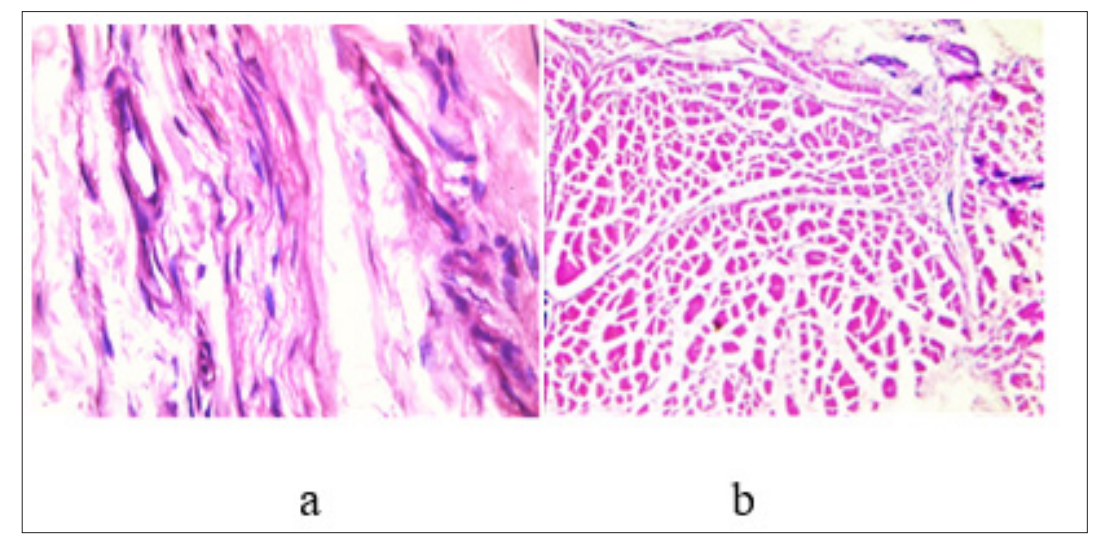

Figure 4a: longitudinal section of SDFT after normal saline therapy showing moderate histopathological changes appeared as round shape cells, multiple hemorrhagic area, moderately increased vascularization and inflammatory cell infiltrate and collagen fibers linearity (20\% to 50\%).(H\&E X40).

Figure 4b: Cross section of SDFT after normal saline therapy showing moderate changes appeared as round shape tendon cells, multiple hemorrhagic area, moderately increased vascularization and inflammatory cell infiltrate (H\&E X 40).

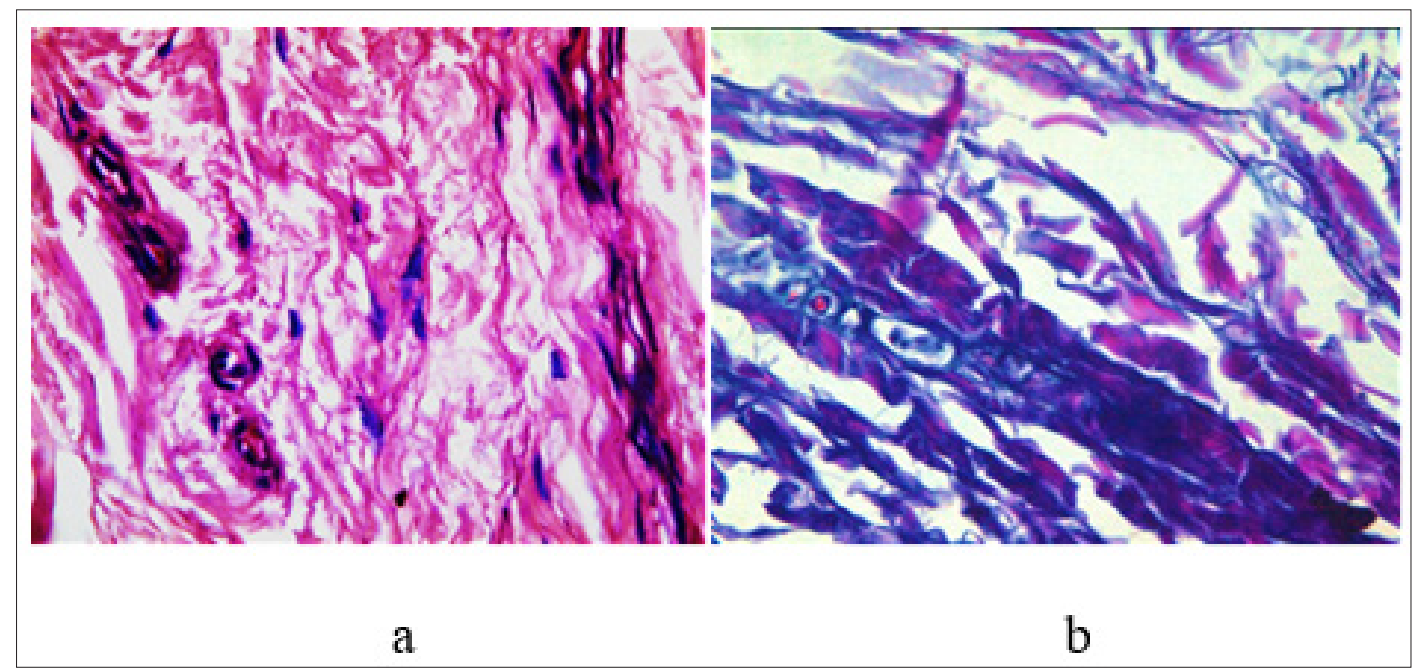

Figure 5a: longitudinal section of SDFT after normal saline therapy showing severe histopathological changes appeared as fragmented tendinous fiber with oedematous granulation tissue and increased vascularization (H\&E X60).

Figure 5b: Longitudinal section of SDFT after normal saline therapy showing severe histopathological changes appeared as round shape of density tendon cells predominant hemorrhagic with high vascularization and inflammatory cell infiltrate and absence of collagen fibers linearity (Masson's trichrome X60).

\section{Discussion}

In the present study, intra-tendon collagenase injection of the SDFTs of the experimental horses successfully caused tendon core lesions in their forelimbs which resemble to a greater extent the naturally developing condition of tendonitis which confirmed clinically by developing of the local inflammatory reaction and ultrasonography by marked deterioration of the echogenicity, linear fiber pattern and MIZ of the tendon fibers core lesions throughout the 2 weeks after induction. Similar technique with collagenase-induced tendonitis had been previously standardized by other authors [17-21]. All the experimental horses exhibited localized heat, swelling and pain over the SDFTs few hours after the induction, indicating inflammation as reported by other authors [20,22]. The lameness evaluation had a high mean score of $(3.4 \pm 0.55)$ during the $1^{\text {st }}$ two weeks after induction The developed signs of inflammation were gradually diminished after 2 weeks from induction. Similar to other study observed the same remission of inflammation after the same duration [17]. However, in other research about the pathogenesis of experimental tendinitis induced with collagenase, traced the presence of persistent local swelling for 14 months after induction [18]. In clinical tendonitis, enzyme degradation by endogenous collagenase and proteases are responsible for lesion enlargement beyond the initial mechanical injury to collagen fibers [17]. In this respect, tendon lesions can be induced by different methods such as the enzymatic by collagenase 
$[15,16]$, physical by FP4 laser [23] or surgical [24]. Although the tendon lesion resulting from the use of collagenase for induction of tendonitis is not identical to the lesion resulting from the etiopathogenesis of a naturally occurring injury, yet collagenase method has several advantages over the other methods such as the development of hyper cellular matrix, the increased vascularization and the absence of inflammation mediated by inflammatory cells in the injured tendon [25].

In the present study, bone marrow harvest via sternal puncture from the $5^{\text {th }}$ sternebra as it was sufficiently caudal to avoid the cranial ventral bony crest, which covers the first 3 sternebrae. Aspiration of bone marrow by Jamshidi biopsy needle, under local anesthesia while the horse was sedated and secured in stanchion and in standing position was feasible and devoid of any side effects. Despite the inconveniency resulted from the operator agitation due to working with the needle in a such critical site. Similar technique had been used in previous studies [13,26,27]. While others used the same technique for bone marrow collection under general anesthesia $[28,29]$. However, using of the biopsy Jamshidi needle and by deep penetration into the sternum under general anesthesia without observing any pain reaction confirming the effectiveness of local anesthetic field block coupled with sedation. It should be mentioned that, bone marrow samples are most consistently obtained from the sternbrae of adult horses, the marrow cavity of the ribs remain hemato-poietically active throughout the life of the horse; however, inadvertent penetration of the intercostal muscles with associated complications including possible pneumothorax or pneumo-pericardium if the needle misdirected from its intended placement of the rib. Therefore, in this study, ultrasonography needle guide was found important for the efficiency of the technique. This is consistent with the results obtained in a previous study [21]. The isolation, culture and expansion resulted in provision of a sufficient amount of MSCs (approximately 10X106 MSCs with 98\% viability after 2 weeks. Similar data were previously obtained [30,31]. The behavior of adult stem cells after their administration is still need further studies, however, it is possible that the stem cells indirectly contribute to recovery by producing bioactive proteins such as growth factors, anti-apoptotic factors and chemotactic agents [32]. These hidden proteins have important effects on local cell dynamics, stimulating vascular ingrowth and recruitment of additional stem cells capable of stimulating recovery [15,32].

Tendon intra/lesional implantation of MSCs under ultrasonography guide gradually improved the outcome of tendon structure, which was evidenced clinically, ultrasonography and morpho histology during the 16th weeks of the experiment. MSCs implantation under sonographic guidance after sedation was shown to be easy technique. This is in agreement with the results of previous studies $[16,21,23]$. The more obvious clinical signs of local inflammation were observed in horses of the experimental group only during the first 2 weeks after MSCs implantation and then disappeared completely by the $12^{\text {th }}$ week. While the horses of the control group exhibited persistent local inflammatory signs throughout the $16^{\text {th }}$ week. There was also similar difference in the degree of lameness between the two groups. The results of the clinical assessment are consistent with previous studies [14,21,27].

Quantitative ultrasonography analysis of longitudinal and cross sectional images revealed a significant differences between the 2 groups throughout the 16 weeks expressed by marked improvement in the scores of echogenicity, linear fiber pattern and cross-sectional lesion area (MIZ\%)in MSCs test group and control group. This result is consistent with those reported in other studies $[14,16,22,27]$. Morphological examination after euthanasia at the week $16^{\text {th }}$ showed smoother surface on the epitenon without bleeding of the tendons of the test group treated with MSCs while, the control group showed marked adhesion and marked scare at the tendon core lesions. These results were confirmed by the quantitative histopathological improvement of the tendons treated test group indicated by a reduction in the inflammatory infiltrate, tendon cells oval-shape, increased vascularization and improved collagen fiber linearity. These data are in agreement with the results of previous studies $[15,16]$. Based on ultrasonography and histopathological results, that the effect of MSCs therapy to tendon lesions has enhanced the tendon repair and this consideration is in accordance with the results previously obtained by other authors who suggested the same effect based on clinical, ultrasonographic and histological studies [22,29]. The enhance healing of connective tissue after MSCs implantation may provide anti-inflammatory, antiapoptic and growth factor stimulatory effect of these multipotent cells $[33,34]$. In this respect, the addition of growth factor for enhancing vascular ingrowth (vascular endothelial growth factor), may play a role in revascularization of the poorly viable core lesion within tendonitis region in horses [35].

\section{Conclusion}

Autologous mesenchymal derived-stem cells have yielded very positive results for the repair of tendon lesions especially when this therapy is executed in the early acute stage. Further studies with long-term follow-up will strengthen the clinical result outcomes.

\section{References}

1. Kasashima Y, Takahashi T, Smith RK, Goodship AE, Kuwano A, et al. (2004) Prevalence of superficial digital flexor tendonitis and suspensory desmitis in Japanese Thoroughbred flat racehorses in 1999. Equine Vet J6: 346-350.

2. Goodship AE, Birch HL, Wilson AM (1994) The pathobiology and repair of tendon and ligament injury. Vet Clin North Am Equine Pract 10(2): 323-349.

3. Williams RB, Harkins LS, Hammond CJ, Wood L (2001) Racehorse injuries, clinical problems and fatalities recorded on British race courses from flat racing and National Hunt racing during 1996, 1997 and 1998. Equine Vet J 33(5): 478-486.

4. Oikawa M, Kasashima Y (2002) The Japanese experience with tendonitis in racehorses. Journal of Equine Science 13(2): 41-56.

5. Marr CM, McMillan I, Boyd JS, Wright NG, Murray M (1993) Ultrasonographic and histopathological findings in equine superficial digital flexor tendon injury. Equine Veterinary Journal 25(1): 23-29.

6. Dyson SJ (2004) Medical management of superficial digital flexor tendonitis: A comparative study in 219 horses (1992-2000) Equine Vet J 36(5): 415-419. 
7. Perkins NR, Reid SW, Morris RS (2005) Risk factors for injury to the superficial digital flexor tendon and suspensory apparatus in thoroughbred racehorses in New Zealand. N Z Vet J 53(3): 184-192.

8. Lam KH, Parkin TD, Riggs CM, Morgan KL (2007) Descriptive analysis of retirement of thoroughbred racehorses due to tendon injuries. Equine Vete J 39(2): 143-148.

9. O Meara BO, Bladon B, Parkin TDH, Fraser B, Lischer CJ, et al. (2010) An investigation of the relationship between race performance and superficial digital flexor tendonitis in the thoroughbred racehorse. Equine Vet J 42(4): 322-326.

10. Marfe G, Rotta G, De Martino L, Tafani M, Fortion F, et al. (2012) A new clinical approach: Use of blood-derived stem cells (BDSCs) for superficial digital flexor tendon injuries in horses. Life Sci 90(21-22): 825-830.

11. Sutter WW, Kaneps AJ, Bertone AL (2004) Comparison of hematologic values and transforming growth factor Association between race history and risk of superficial digital flexor tendon injury in thoroughbred racehorses. Journal of the American Veterinary Medical Association 225: 90-93.

12. Anitua E, Andia I, Sanchez M, Azofra J, Del Mar Zalduendo M, et al. (2005) Autologous preparations rich in growth factors promote proliferation and induce VEGF and HGF production by human tendon cells in culture. J Orthop Res 23(2): 281-286.

13. Smith RK, Korda M, Blunn GW, Goodship AE (2003) Isolation and implantation of autologous equine mesenchymal stem cells from bone marrow into the superficial digital flexor tendon as a potential novel treatment. Equine Vet J 35(1): 99-102.

14. Crovace A, Lacitignola L, Rossi G, Francioso E (2010) Histological and immunohistochemical evaluation of autologous cultured bone marrow mesenchymal stem cells and bone marrow mononucleated cells in collagenase-induced tendinitis of equine superficial digital flexor tendon. Vet Med Int 2010: 250978.

15. Nixon AJ, Dahlgren LA, Haupt JL, Yeager AE, Ward DL (2008) Effect of adipose-derived nucleated cell fractions on tendon repair in horses with collagenase-induced tendinitis. Am J Vet Res 69(7): 928-937.

16. Carvalho A, Alves A, de Oliveira P, Alvarez LEC, Amorim RL, et al. (2011) Use of adipose tissue-derived mesenchymal stem cells for experimental tendinitis therapy in equines. Journal of Equine Veterinary Science 31(1): 26-34.

17. Silver IA, Brown PN, Goodship AE, Lanyon LE, McCullagh KG, et al (1983) A clinical and experimental study of tendon injury, healing and treatment in the horse. Equine Vet J Suppl 1: 1-43.

18. Williams IF, McCullagh KG, Goodship AE, Silver IA (1984) Studies on the pathogenesis of equine tendonitis following collagenase injury. Res Vet Sc 36(3): 326-338

19. Spurlock GH, Parker GA (1989) Ultrasonographic, gross, and histologic evaluation of a tendinitis disease in the horse. Vet Radiol 30(4): 184-188.

20. Marxen S, Lacerda Neto JC, Canola JC, Moraes JRE, Riberio G (2004)) Intralesional polysulphated glycosaminoglycan as treatment of equine collagenase induced tendinitis: clinical, ultrasonographic and histopathologic evaluation. Arq Bras Med Vet Zootec 56(6): 701-708.

21. Barreira APB, Alves ALG, Saito M (2008) Autologous implant of bone marrow mononuclear cells as treatment of induced equine tendinitis.
Int J Appl Res Vet Med 6: 46-54

22. Dahlgren LA, Mohamed HO, Nixon AJ (2005) Temporal expression of growth factors and matrix molecules in healing tendon lesions. J Orthop Res 23(1): 84-92.

23. Minnema S (2013) An introduction to FP4 laser with equine SDFT injuries in combination with an ex vivo comparative study: How to induce core lesions in equine tendons in a standardized fashion department of comparative physiology, Ghent University, Belgium. Faculty of Veterinary Medicine, Utrecht University, Netherlands.

24. Schramme M, Hunter S, Campbell N, Blikslager A, Smith R (2009) Surgical tendonitis model in horses: Technique, clinical, ultrasonographic and histological characterisation. Vet Comp Orthop Traumatol 23(4): 231239.

25. Dirks RC, Warden SJ (2011) Models for the study of tendinopathy. J Musculoskelet Neuronal Interact 11(2): 141-149.

26. Pacini S, Spinabella S, Trombi L, Fazzi R, Galimberti S, et al. (2007) Suspension of bone marrow-derived undifferentiated mesenchymal stromal cells for repair of superficial digital flexor tendon in racehorses. Tissue Eng 13(12): 2949-2955.

27. Kasashima Y, Ueno T, Tomita A, Goodship AE, Smith RKW (2011) Optimization of bone marrow aspiration from the equine sternum for the safe recovery of mesenchymal stem cells. Equine Vet J 43(3): 288294.

28. Herthel D (2002) Enhanced suspensory ligament healing in 100 horses by stem cells and other bone marrow components. Proc Am Assoc Equine Pract 47: 319.

29. Violini S, Ramelli P, Pisani LF, Gorni C, Mariani P (2009) Horse bone marrow mesenchymal stem cells express embryo stem cell markers and show the ability for tenogenic differentiation by in vitro exposure to BMP-12. BMC Cell Biol 10: 29.

30. Vidal MA, Kilroy GE, Lopez MJ, Johnson JR, Moore RM, et al. (2007) Characterization of equine adipose tissue derived stromal cells: Adipogenic and osteogenic capacity and comparison with bone marrow derived mesenchymal stromal cells. Vet Surg 36(7): 613-622.

31. Burk J, Berner D, Brehm W, Hillmann A, Horstmeier C, et al. (2016) Longterm cell tracking following local injection of mesenchymal stromal cells in the equine model of induced tendon disease. Cell Transplant 25(12): $2199-2211$.

32. Rehman J, Traktuev D, Li J, Merfeld-Clauss S, Temm-Grove CJ, et al.(2004) Secretion of angiogenic and antiapoptotic factors by human adipose stromal cells. Circulation 109(10): 1292-1298.

33. Puissant B, Barreau C, Bourin P, Clavel C, Corre J, et al. (2005) Immunomodulatory effect of human adipose tissue-derived adult stem cells: Comparison with bone marrow mesenchymal stem cells. $\mathrm{Br}$ J Haemato 129(1): 118-129.

34. Wolbank S, Peterbauer A, Fahrner M, Hennerbichler S, Van Griensven M et al. (2007) Dose-dependent immunomodulatory effect of human stem cells from amniotic membrane: A comparison with human mesenchymal stem cells from adipose tissue. Tissue Eng 13(6): 1173-1183.

35. Molloy T, Wang Y, Murrell G ( 2003) The roles of growth factors in tendon and ligament healing. Sports Med 33(5): 381-394. 